\title{
Effect of Oral Clonidine Premedication in Diabetic Patients on Haemodynamic Status and Blood Glucose Homeostasis - A Comparative Study
}

Mohammad Sofiuddin ${ }^{1}$, Dilip Kumar Bhowmick ${ }^{2}$, Md. Shafiqul Islam ${ }^{3}$, Mohammad Abdul Wahab ${ }^{4}$, Mir Mohammad Rifat Chowdhury ${ }^{5}$, Nepal Chandra Saha ${ }^{6}$, Akhtaruzzaman $\mathrm{AKM}^{7 *}$

${ }^{1}$ Assistant Professor, Department of Anaesthesia, Intensive Care \& Pain Medicine, Shaheed Syed Nazrul Islam Medical College, Kishoreganj, Bangladesh

${ }^{2}$ Associate Professor, Department of Anaesthesia, Analgesia and Intensive Care Medicine, Bangabandhu Sheikh Mujib Medical University, Dhaka, Bangladesh

${ }^{3}$ Associate Professor, Department of Anaesthesia, Analgesia and Intensive Care Medicine, Bangabandhu Sheikh Mujib Medical University, Dhaka, Bangladesh

${ }^{4}$ Assistant Professor, Department of Anaesthesia, Intensive Care \& Pain Medicine, Shaheed Syed Nazrul Islam Medical College, Kishoreganj, Bangladesh

${ }^{5}$ Junior Consultant, Department of Cardiac Anaesthesiology, National Heart Foundation Hospital and Research Institute, Mirpur, Dhaka, Bangladesh ${ }^{6}$ Consultant, Department of Anaesthesiology, Ibne Sina Specialized Hospital (Cardiac Unit), Dhaka, Bangladesh

${ }^{7}$ Professor and Chairman, Department of Anaesthesia, Analgesia and Intensive Care Medicine, Bangabandhu Sheikh Mujib Medical University, Dhaka, Bangladesh

DOI: $10.36347 /$ siams.2020.v08i08.034

| Received: 16.08.2020 | Accepted: 23.08.2020 | Published: 30.08.2020

*Corresponding author: Akhtaruzzaman AKM

Abstract

Original Research Article

Background: In stressful conditions, raising haemodynamic parameters and blood glucose concentration are closely related to an increase in catecholamines and cortisol release. Clonidine, a centrally acting $\alpha_{2}$-adrenoceptor agonist has neuroendrocrine effects including inhibition of sympathoadrenal activity and ACTH \& cortisol release. Therefore, clonidine premedication during surgery has been proposed as a way of improving perioperative haemodynamic status and blood glucose control in diabetic patients. Objectives: The present study was designed to observe the effects of oral clonidine premedication on blood glucose control and haemodynamic status in type-II diabetic patients undergoing major gynaecological surgery under general anaesthesia. Methods: A total number of sixty female type-II diabetic patients were selected randomly into two groups, thirty in each group. Group-A (control) received no premedication and Group-B (experimental) received oral clonidine $(100 \mu \mathrm{g}) 90$ minutes before surgery. Patients were given insulin by continuous IV infusion to maintain blood glucose in the range of 5.5-11.1 mmol litre . $^{-1}$. Haemodynamic parameters were measured every $10 \mathrm{~min}$ interval and blood glucose concentrations were measured every $30 \mathrm{~min}$ during surgery \& hourly for $4 \mathrm{~h}$ after surgery. Total requirement of insulin for both groups were calculated during the period. Results: Haemodynamic parameters of the clonidine group were significantly stable $(\mathrm{p}<0.01)$ in comparison to control group. Glycaemia was significantly lower in the clonidine group $(\mathrm{p}<0.001)$ and the total amount of insulin administered was significantly reduced: clonidine group $9.3 \pm 0.5$ units; control group $17.8 \pm 0.6$ units $(\mathrm{p}=0.000)$. Conclusion: Clonidine premedication in type-II diabetic patients 90 min before surgery ensures haemodynamic stability, blood glucose control and decreases insulin requirement during major gynaecological surgery under general anaesthesia.

Keywords: Clonidine, haemodynamics, diabetes, blood glucose, catecholamines, insulin.

Copyright @ 2020: This is an open-access article distributed under the terms of the Creative Commons Attribution license which permits unrestricted use, distribution, and reproduction in any medium for non-commercial use (NonCommercial, or CC-BY-NC) provided the original author and source are credited.

\section{INTRODUCTION}

The objective of general anaesthesia is to render patient unconscious and unaware of his/her surroundings, to attenuate response to surgical and anaesthetic stress and to produce muscle relaxation to facilitate tracheal intubations and to provide paralysis to allow easy access to body cavities. Anaesthesia in presence of co-existing systemic disease, different anaesthetic techniques and procedures including proper selection of drugs are being applied to provide a safe landing from anaesthesia and good perioperative condition. 
Diabetes mellitus is the most common endocrine abnormality encountered in surgical patients and is associated with increased perioperative morbidity and mortality [1]. That is why proper attention is needed to keep the blood glucose within acceptable range in these group of patients in the perioperative period otherwise they may develop ketosis and acidaemia /or may be susceptable to electolytes imbalance and volume depletion from osmotic diuresis. There is impairment of wound strength and wound healing with a plasma glucose level of $>11.1 \mathrm{mmol} / \mathrm{l}$. The leucocyte functions of chemotaxis, opsonisation and phagocytosis are also affected by hyperglycaemia [2]. Tight long-term control of blood glucose and blood pressure improve outcome in these patients. The same philosophy of management is being applied to the perioperative period. So it is important to maintain stable haemodynamic and glycaemic control during perioperative period which ensures better outcome.

Surgery especially in the presence of general anaesthesia produces a diabetogenic response. Surgical stress leads to reproducible physiological, metabolic and hormonal responses, characterised by an altered carbohydrate metabolism, a net loss of protein and an increased lipolysis. They are due to an increased secretion of catecholamines, ACTH, cortisol and cytokines [3]. In patients with diabetes undergoing surgery, the therapeutic strategy must be to mimic normal metabolism as closely as possible.

In stressful conditions, and particularly in diabetes mellitus, the release of epinephrine and norepinephrine results in excessive hyperglycaemia. The pivotal role of catecholamines manifests itself in their glycogenolytic and lipolytic effects, in suppressed insulin activity and in stimulation of the pituitary adrenocortical axis. Catecholamines increase the hepatic production of glucose, and this response is intensified by the increased sensitivity of the tissues of diabetic patients to catecholamines. Cortisol prolongs and amplifies the hyperglycaemic effects of catecholamines by stimulating gluconeogenesis, and by increasing insulin resistance [4]. The increase in blood glucose in diabetic patients during the first hours of a stressful event is closely related to an increase in catecholamines.

Diabetic patients frequently have cardiovascular disorders such as hypertension, ischaemic heart disease and left ventricular dysfunction and very often associated with autonomic neuropathy which may aggravate during instrumentation of airway and anaesthesia. Therefore, effective measures are to be sought to reduce these responses and minimize intraoperative hazards.

Clonidine, an $\alpha_{2}$-adrenoceptor agonist, reduces sympathetic tone and the release of norepinephrine from nerve terminals [5]. There is controversy concerning the effect of clonidine on the pituitary adrenocortical system, but decreased release of adrenocorticotrophic hormone (ACTH) and cortisol has been reported. Therefore, the use of clonidine during surgery has been proposed as a way of improving perioperative haemodynamics, decreasing both the intracranial pressure and anaesthetic requirements [6].

Therefore, the use of clonidine to suppress increased catecholamine release and thus improve blood glucose control during surgery is rationalapproach. $\alpha_{2}$ adrenoceptor agonists inhibit the release of catecholamines through the activation of central presynaptic inhibitory $\alpha_{2}$-adrenoceptors and there is a dose-dependent reduction in the plasma catecholamine concentration after oral clonidine [7]. This central and peripheral effect of clonidine may explain the improvement in metabolic control. Clonidine given as a premedication improves cardiovascular stability and blunts the cardiovascular response to laryngoscopy, intubation and surgery [8]. These properties are useful in diabetic patients undergoing surgery. Clonidine also reduces intracranial pressure and prevents an increase in intracranial pressure resulting from the acute hypertension that occurs during airway instrumentation and surgical stimulation.

In this study we have compared the effect of clonidine pretreatment in intraoperative haemodynamics, perioperative glycaemic status and total requirement for insulin in diabetic patients undergoing major gynaecological surgery under general anaesthesia.

\section{Methods}

This randomized single blind prospective study was carried out in the Department of Anaesthesia, Analgesia and Intensive Care, Bangabandhu Sheikh Mujib Medical University with approval of the University Ethical Reveiw Committee. The study was performed with informed written consent of Sixty female type-II diabetic patients who were randomly divided into two groups (30 in each group). The control group (Group-A) received no premedication and the experimental group (Group-B) received oral clonidine premedication $(100 \mu \mathrm{g}) 90 \mathrm{~min}$ before surgery.

None of the patients received $\beta$-blockers, antidepressants, neuroleptics, corticosteriods, catecholamines or NSAIDs before or during surgery. None of them was treated with $\alpha_{2}$-adrenoceptor agonists before surgery.

Insulin and sulfonylurea hypoglycaemics was discontinued the night before surgery, and biguanides 72 hours before surgery. All patients fasted from the night before surgery. 
Demographic data including age, weight, and physical status, duration of diabetes and duration of surgery were recorded for all subjects. Surgical cases for the study were selected as such that the total operative procedure required near about 1.5 hours.

Insulin therapy was started just before induction of anaesthesia. Patients received a shortacting insulin (Actrapid HM) 1.25 units/h by continuous i.v. infusion from a pump-driven syringe (model no.STC-527, TERUMO, Japan) (40 units in $31 \mathrm{ml} \mathrm{0.9 \%}$ saline solution; 1.25 units $=1 \mathrm{ml})$ through a separate peripheral cannula. The problem of insulin adsorption in the syringe was overcome by using high concentrations of insulin and allowing the first $4 \mathrm{ml}$ to flush through the apparatus. Concurrently, a continuous infusion of $5 \%$ glucose was given via the same venous cannula at $125 \mathrm{ml} / \mathrm{h}(6.25 \mathrm{~g} / \mathrm{h})$. A second venous cannula was used to infuse other medications or $0.9 \%$ saline for volume expansion. (Fluids containing glucose and lactate were avoided.)

Anaesthesia was induced when the blood glucose between 5.5 and $11.1 \mathrm{mmol} /$ litre $^{12}$. If the concentration was less than $5.5 \mathrm{mmol} / \mathrm{litre}$, the rate of glucose infusion was briefly increased; if it was greater than $11.1 \mathrm{mmol} /$ litre, additional insulin (5 units) was given as an IV bolus until blood glucose less than 11.1 mmol/litre. In both groups, when blood glucose exceeded $11.1 \mathrm{mmol} / \mathrm{litre}$ during or after surgery, an additional i.v. bolus of insulin was given in the following fashion: 5 units if blood glucose in the range 11.1-14.0 mmol/litre; 7 units if blood glucose in the range 14.0-17.0 mmol/litre; 10 units if blood glucose greater than $17.0 \mathrm{mmol} / \mathrm{litre}$.
Induction of anaesthesia (both groups) was done with thiopental $4-5 \mathrm{mg} / \mathrm{kg}$ and tracheal intubation was facilitated with vecuronium $0.1 \mathrm{mg} / \mathrm{kg}$. Fentanyl was used at induction $2 \mu \mathrm{g} / \mathrm{kg}$ and during anaesthesia. Anaesthesia was maintained with $0.5 \%-0.8 \%$ halothane in $66 \%$ nitrous oxide in oxygen. Muscle relaxation was maintained with vecuronium. Ventilation was controlled to maintain $\mathrm{E}_{\mathrm{T}} \mathrm{CO}_{2}$ between 35 and $40 \mathrm{~mm}$ $\mathrm{Hg}$ (Agilent, model v243).

Observation for the study was begun just before induction and ended 6 hours on ward during and after surgery. Systolic, diastolic and mean arterial pressure were measured and heart rate was recorded from the automatic device (Agilent, model v243) just before induction and every 10 mins interval during operation. Capilary blood glucose was measured just before induction and every 30 mins during surgery \& hourly up to four hours in the postoperative period using reagent strips (Home blood glucose monitoring device, ACCU-CHEK Active, Roche).

\section{STATISTICAl Analysis}

Data were compiled and analyzed for statistical significance using unpaired Student's ' $t$ '-test and Chisquare $\left(\chi^{2}\right)$ test as appropriate. Data were expressed as mean \pm SD or in frequencies as applicable. A ' $p$ '-value of less than 0.05 was considered statistically significant (CL-95\%).

\section{RESULTS}

Two groups matched statistically comprising age $(\mathrm{p}=0.437)$, weight $(\mathrm{p}=0.582)$ ASA status $(\mathrm{p}=0.375)$, duration of diabetes $(\mathrm{p}=0.521)$ and duration of surgery $(\mathrm{p}=0.610)$ revealing in different status (Table-1).

Table-1: Demographic variables

\begin{tabular}{|l|l|l|l|}
\hline \multirow{2}{*}{\multicolumn{1}{|c|}{ Variables }} & \multicolumn{2}{c|}{ Group } & \multicolumn{1}{c|}{ p - value } \\
\cline { 2 - 4 } & \multicolumn{1}{|c|}{$\mathbf{A}(\mathbf{n}=\mathbf{3 0})$} & \\
\hline Age(years) & $44.3 \pm 3.9$ & $42.7 \pm 4.3$ & 0.437 \\
\hline Weight (kg) & $53.2 \pm 6.355 .8 \pm 5.1$ & 0.582 & \\
\hline Physical status & & & \\
\hline ASA grade-II & $26(86.66)$ & $23(76.66)$ & 0.375 \\
\hline ASAgrade-III & $4(13.33)$ & $7(23.33)$ & \\
\hline Duration of diabetes (yr) & $9.1 \pm 1.4$ & $8.6 \pm 1.2$ & 0.521 \\
\hline Duration of surgery (min) & $92 \pm 8$ & $95 \pm 7$ & 0.610 \\
\hline
\end{tabular}

*All values were presented as mean \pm SD or in frequencies. Data were analysed using unpaired student's t-test and Chi-square test as appropriate.p-value $<0.05$ were considered stastistically significant.

\section{Baseline preoperative characteristics of the patients} Haemodynamic variables like heart rate $(p>0.05)$, mean arterial blood pressure $(p>0.05)$ and blood glucose level $(\mathrm{p}>0.05)$ at preoperative baseline were identical in both groups which were insignificant statistically (Table-2). 
Table-2: Base line (Preoperative) parameters of the patients

\begin{tabular}{|l|l|l|l|}
\hline \multirow{2}{*}{ Variables } & \multicolumn{2}{|l|}{ Group } & \multirow{2}{*}{ p - value } \\
\cline { 2 - 3 } & $\mathbf{A}(\mathbf{n}=\mathbf{3 0})$ & $\mathbf{B}(\mathbf{n}=\mathbf{3 0})$ & \\
\hline Heart Rate (beats/min) & $82.5 \pm 6.3$ & $79.2 \pm 8.8$ & $\mathrm{p}>0.05$ \\
\hline Mean BP (mm Hg) & $92.4 \pm 13.0$ & $89.33 \pm 11.2$ & $\mathrm{p}>0.05$ \\
\hline Blood Glucose (m.mol/L) & $7.1 \pm 0.6$ & $6.9 \pm 0.3$ & $\mathrm{p}>0.05$ \\
\hline
\end{tabular}

*Values were expressed as mean $\pm \mathrm{SD}$, unpaired Student's t-Test was used to analyse the data.

Comparison of heart rate and mean arterial pressure at different time interval

Heart rate in Group-B found gradually declined (Table-3) but became stable later. On the contrary marked fluctuations was observed in Group-A. Statistically significant difference $(p<0.001)$ found between the groups.

Table-3: Intra-operative monitoring of Heart Rate

\begin{tabular}{|l|c|c|c|}
\hline \multirow{2}{*}{ Heart Rate(beat/min) } & \multicolumn{2}{|c|}{ Group } & \multirow{2}{*}{ p - value } \\
\cline { 2 - 3 } & $\mathbf{A}(\mathbf{n}=\mathbf{3 0})$ & $\mathbf{B}(\mathbf{n}=\mathbf{3 0})$ & \\
\hline At base line & $82.5 \pm 6.3$ & $79.2 \pm 8.8$ & $\mathrm{p}>0.05$ \\
\hline Just after intubation & $97 \pm 11$ & $90 \pm 8$ & $\mathrm{p}<0.01$ \\
\hline 10 mins after & $84 \pm 9$ & $82 \pm 7$ & $\mathrm{p}>0.05$ \\
\hline 20 mins after & $83 \pm 7$ & $73 \pm 5$ & $\mathrm{p}<0.001$ \\
\hline 30 mins after & $93 \pm 9$ & $70 \pm 4$ & $\mathrm{p}<0.001$ \\
\hline 40 mins after & $86 \pm 7$ & $73 \pm 6$ & $\mathrm{p}<0.001$ \\
\hline 50 mins after & $83 \pm 6$ & $68 \pm 4$ & $\mathrm{p}<0.001$ \\
\hline 60 mins after & $74.4 \pm 8$ & $60.8 \pm 5$ & $\mathrm{p}<0.001$ \\
\hline 70 mins after & $80 \pm 8$ & $67 \pm 4$ & $\mathrm{p}<0.001$ \\
\hline 80 mins after & $81 \pm 8$ & $78 \pm 6$ & $\mathrm{p}>0.05$ \\
\hline 90 mins after & $98 \pm 12$ & $83 \pm 7$ & $\mathrm{p}<0.001$ \\
\hline
\end{tabular}

*Data were analysed using unpaired student's t-Test and values were presented as mean \pm SD.

Mean arterial blood pressure though having significant difference $(\mathrm{p}<0.05)$ between groups but fluctuations was observed more in Group-A and more stable decline in Group-B (Figure-1).

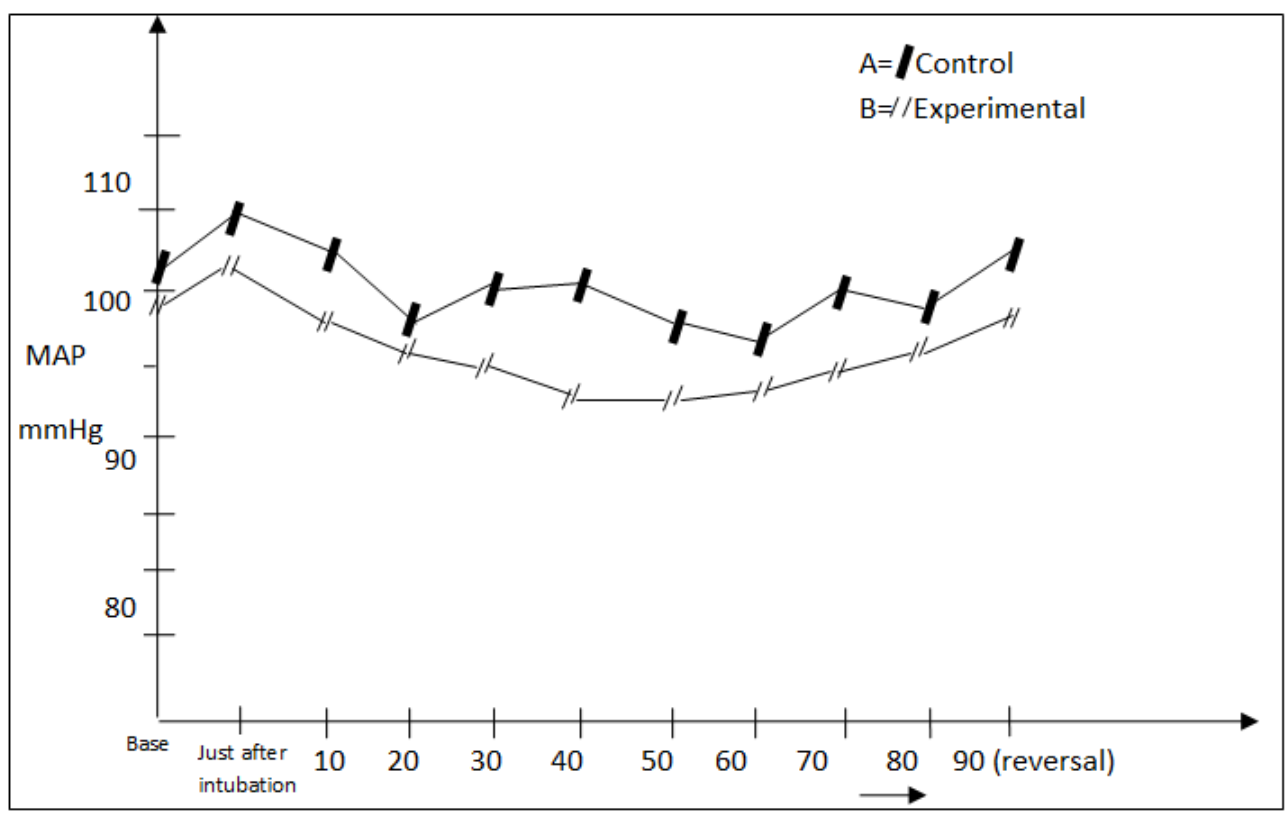

Fig-1: Comparison of mean arterial pressure at different time interval

Comparison of blood glucose at different time interval:

Preoperative blood glucose level between groups did not vary significantly $(p>0.05)$. Blood glucose was relatively stable in experimental group (ranged from 6.9-9.8mmol/1) than control group (ranged from7.1-11.6 mmol/l) and the differences were sigficant statistically $(\mathrm{p}<0.01)$ during both intra and postoperative period (Table-5). 
Table-5: Monitoring of intra \& postoperative Blood glucose

\begin{tabular}{|l|c|c|c|}
\hline \multirow{2}{*}{ Blood glucose (mmol/l) } & \multicolumn{2}{|c|}{ Group } & \multirow{2}{*}{ p - value } \\
\cline { 2 - 3 } & $\mathbf{A}(\mathbf{n}=\mathbf{3 0})$ & $\mathbf{B}(\mathbf{n}=\mathbf{3 0})$ & \\
\hline At base line & $7.1 \pm 0.6$ & $6.9 \pm 0.3$ & $\mathrm{p}>0.05$ \\
\hline Intraoperative & $8.7 \pm 0.5$ & $7.2 \pm 0.3$ & $\mathrm{p}<0.001$ \\
\hline 30 minsafter induction & $11.6 \pm 0.6$ & $9.8 \pm 0.5$ & $\mathrm{p}<0.001$ \\
\hline 60 mins after & $9.7 \pm 0.4$ & $8.5 \pm 0.3$ & $\mathrm{p}<0.001$ \\
\hline 90 mins after & $10.6 \pm 0.7$ & $8.7 \pm 0.4$ & $\mathrm{p}<0.001$ \\
\hline Postoperative & $11.3 \pm 0.8$ & $9.1 \pm 0.5$ & $\mathrm{p}<0.001$ \\
\hline 1 hour after reversal & $10.7 \pm 0.6$ & $8.4 \pm 0.4$ & $\mathrm{p}<0.001$ \\
\hline 2 hour after & $10.2 \pm 0.5$ & $7.8 \pm 0.3$ & $\mathrm{p}<0.001$ \\
\hline 3 hour after & \multicolumn{3}{|l}{} \\
\hline 4 hour after & Data are analysed using unpaired student's t-Test and values were expressed as mean \pm SD.
\end{tabular}

\section{Comparison of total insulin requirement in between two groups}

Total insulin requirements during intra and postoperative 6 hours period were $17.8 \pm 0.6$ and $9.3 \pm 0.5$ units both in control and experimental groups respectively. More consumption of insulin was noted in control group which became highly significant $(\mathrm{p}<0.00)$ statistically (Table-6).

Table-6: Total requirement of Insulin

\begin{tabular}{|l|r|r|r|l|}
\hline & \multicolumn{2}{|c|}{ Group } & \multirow{2}{*}{ p-value } & \multirow{2}{*}{ Significance level } \\
\cline { 2 - 3 } & $\mathrm{A}(\mathrm{n}=30)$ & $\mathrm{B}(\mathrm{n}=30)$ & & \\
\hline Total insulin required (units) & $17.8 \pm 0.6$ & $9.3 \pm 0.5$ & 0.000 & ${ }^{* *} \mathrm{HS}$ \\
\hline
\end{tabular}

*Data areanalysed using unpairedstudent's t-Test and expressed as mean $\pm \mathrm{SD} ;{ }^{* *} \mathrm{HS}-\mathrm{Highly}$ significan

\section{DiSCUSSION}

Diabetes mellitus is the most common endocrine disorder and a vast majority of population with diabetes requires surgery in their lifetime. This study was conducted in sixty adult female patients belonging to ASA physical status II and III to observe the effect of oral clonidine on intra-operative haemodynamic status as well as perioperative blood glucose homeostasis and insulin requirement in type-II diabetic patients who underwent major gynaecological abdominal surgery under general anaesthesia. Oral clonidine was given as premedication to the experimental group and no premedication was given to control group.

Demographic data and preoperative baseline haemodynamic parameters were almost identical in both groups $(\mathrm{p}>0.05)$. Prefixed stable EtCO2 and $\mathrm{SpO}_{2}$ were maintained for each patient throughout the intraoperative period. $\mathrm{EtCO}_{2}$ was kept between $35-40 \mathrm{~mm}$ of $\mathrm{Hg} . \mathrm{SpO}_{2}$ was maintained in between $98-100 \%$.

Matot published their study on effect of clonidine pre-medication on haemodynamic responses to fiber optic bronchoscopy [9]. It was a prospective randomized double blind study. According to the result of their study, $76 \%$ of patients who were given $300 \mu \mathrm{g}$ of clonidine as pre-anaesthetic medication have reduced blood pressure and pulse rate intra-operatively. In our study, we have compared the changes in BP between experimental and control group
Jellish used oral clonidine $(5 \mu \mathrm{g} / \mathrm{kg})$ as preanaesthetic medication and observed the fluctuation of mean arterial pressure during head pin insertion in case of skull base procedure [10]. According to their study fluctuation of mean arterial pressure was minimum. We observed the changes in mean pressure at different time intervals following intubation. The mean pressure of the experimental group decreased steadily throughout the intra-operative period, while that of the control group showed fluctuation in successive period of evaluation and overshoot the baseline level at the time of reversal.

Benedikter published their study on effect of oral clonidine on blood pressure and heart rate in normotensive subjects [11]. In their study, they found $150 \mu \mathrm{g}$ oral clonidine produced a significant reduction in systolic and diastolic blood pressures, both in supine and standing position. We have studied the changes in heart rate of experimental and control groups. Just after intubation, the heart rates of both the groups were increased but the change in heart rate of control group was more and statistically significant $(\mathrm{p}<0.05)$. Besides, the heart rate of the experimental group showed little variations throughout the intraoperative period but the heart rate of the control group showed significant variations in the same period and markedly raised at the time of reversal $(\mathrm{p}<0.001)$.

From the monitoring data of heart rate, and mean arterial pressure, our study revealed that the haemodynamic state of the experimental group that received oral clonidine at least 90 minutes before general anaesthesia remained more stable condition 
throughout the intraoperative period compared to the control group that received no premedication.

Raucoules-Aime published their study on effect of 0063lonidine on metabolic control in type-II diabetic patients during ophthalmic surgery [12]. They found that premedication with clonidine $4 \mu \mathrm{g} / \mathrm{kg} 90$ mints before surgery improves blood glucose control and decreases insulin requirements.

We studied intra and postoperative blood glucose as well as total requirement of insulin in the first 6 hour of post operative period. In experimental group mean preoperative (baseline) blood glucose was $6.9( \pm 0.3) \mathrm{mmol} / \mathrm{l}$ and every intra and postoperative evaluation time it was remained within expected range (5.5-11.1 m.mol/l). In contrast, the mean baseline blood glucose of control group was $7.1( \pm 0.6) \mathrm{mmol} / \mathrm{l}$ and exceeded highest expected range 60 mints after intubation $(11.6 \mathrm{~m} . \mathrm{mol} / \mathrm{l})$ in the intraoperative period and 2hour after reversal $(11.3 \mathrm{~m} . \mathrm{mol} / \mathrm{l})$ in the postoperative period. Moreover, at every successive level of evaluation the raised blood glucose of control group was statistically significant $(\mathrm{p}<0.001)$.

Regarding requirement of total insulin during intra and postoperative evaluation period ( 6 hours), the mean insulin required for experimental group was $9.3( \pm 0.5)$ units where as control group required $17.8( \pm 0.6)$ units. The required insulin for control group as compared to experimental group was statistically highly significant $(\mathrm{p}=0.000)$.

\section{Conclusion}

Under the condition of present study it can be concluded that clonidine oral premedication effectively reduce insulin requirement and maintain haemodynamic status in diabetic patient required major gynaecological surgery under general anaesthesia.

\section{REFERENCES}

1. Davies NJH, Cashman JN. Lee's Synopsis of Anaesthesia, $13^{\text {th }}$ edition, Elsevier, India, 2006; 4445.

2. Hickman MS, Schwesinger WH, Page CP. Acute cholecystitis in the diabetic: a case-control study of outcome. Archives of Surgery. 1988 Apr 1;123(4):409-11.
3. Chambrier C, Bouletreau P. Epidural anaesthesia and metabolic response to surgical stress. Am J Hosp pharm. 1994; 51(12):1539-54.

4. Weissman C. The Metabolic Response to StressAn Overview and Update. Anesthesiology: The Journal of the American Society of Anesthesiologists. 1990 Aug 1;73(2):308-27.

5. Quintin L, Roudot F, Roux C, Macquin I, Basmaciogullari A, Guyene T, Vaubourdolle M, Viale JP, Bonnet F, Ghignone M. Effect of clonidine on the circulation and vasoactive hormones after aortic surgery. BJA: British Journal of Anaesthesia. 1991 Jan 1;66(1):108-15.

6. Morgan GE, Mikhali MS, Murray MJ. Clinical Anesthesiology, $3^{\text {rd }}$ edition, New York, McGrawHill, 2006; 217.

7. Mikawa K, Nishina K, Maekawa N, Obara H. Oral clonidine premedication reduces postoperative pain in children. Anesthesia \& Analgesia. 1996 Feb $1 ; 82(2): 225-30$

8. Engelman E, Lipszyc M, Gilbart E, Van der Linden P, Bellens B, Van Romphey A, De Rood M. Effects of clonidine on anesthetic drug requirements and hemodynamic response during aortic surgery. Anesthesiology: The Journal of the American Society of Anesthesiologists. 1989 Aug 1;71(2):178-87.

9. Matot I, Kuras Y, Kramer MR. Effect of clonidine premedication on haemodynamic responses to fibreoptic bronchoscopy. Anaesthesia. 2000 Mar;55(3):269-74.

10. Jellish WS, Theard MA, Cheng MA, Leonetti JP, Crowder CM, Tempelhoff R. The effects of clonidine premedication and scalp infiltration of lidocaine on hemodynamic responses to laryngoscopy and skull pin head-holder insertion during skull base procedures. Skull Base. 2001 Aug;11(3):169-176.

11. Benedikter L, Mey T, Middleton DA. Comparative study of the effect of azepexole and clonidine on blood pressure and pulse rate in normotensive subjects. European journal of clinical pharmacology. 1981 Sep 1;20(5):321-8.

12. Belhoula M, Ciebiera JP, De La Chapelle A, Boisseau N, Coeurveille D, Raucoules- Aimé M. Clonidine premedication improves metabolic control in type 2 diabetic patients during ophthalmic surgery. British journal of anaesthesia. 2003 Apr 1;90(4):434-9. 